\title{
Novel Drying Process Assisted by Microwave to Iron Ore Pelletizing
}

\author{
Maycon Athayde ${ }^{a *},{ }^{-}$Maurício Covcevich Bagatini ${ }^{a}$, Maurício Cota Fonseca ${ }^{b}$ \\ ${ }^{a}$ Departamento de Engenharia de Metalúrgica e de Materiais, Universidade Federal de Minas Gerais, \\ Belo Horizonte, $M G$, Brasil \\ ${ }^{b}$ Samarco Mineração S/A, Anchieta, ES, Brasil
}

Received: March 06, 2018; Revised: May 22, 2018; Accepted: July 17, 2018

\begin{abstract}
Drying has became critical to iron ore pellet production, due to increasing inability to withdrawal moisture from the green pellets, especially faced by goethitic iron ore producers. Most of the existing pelletizing furnaces do not support increase heating rates nor changes in furnaces length, without compromise pellet quality. The present study evaluates an innovative alternative for the actual fully convective drying process composed by an up-draught drying (UDD) and down-draught drying stage (DDD), through the application of microwave energy to assist the existing process. In the present work, the process was simulated in a pot grate where industrial parameters can be simulated. The microwave generator (power input of $10 \mathrm{MW}$ and $915 \mathrm{MHz}$ ) was connected in a traditional static pot grate at the hood by a microwave conductor. The experiments show elimination of the over-wet zone at the upper layer of pellet observed at the traditional process. A reduction greater than $7 \%$ of the moisture in UDD was achieved, while the convective process adds extra moist to the green pellets modifying the pellet shape.
\end{abstract}

Keywords: Drying, Microwave, Travelling Grate, Pellet.

\section{Introduction}

Pelletizing has great importance in iron ore mining, ensuring optimal use of mineral reserves and increases the overall blast furnace efficiency. In general, the process involves two main steps, firstly the balling, where green pellets are formed with the addition of a binder to enhance agglomeration, induced by water and capillary forces formed within the iron ore grains ${ }^{1}$. Secondly, the pellets are treated in induration furnace to attain mechanical resistance and appropriate metallurgical characteristics required by the ironmaking facilities ${ }^{2}$. The travelling grate furnace, where the induration process is carried out, is generally divided into 4 zones: drying, pre-heating, firing and cooling. A great energy amount is consumed during the induration process (i.e. in the form of natural gas, oil, tar, anthracite or coke). Due to fossil fuel scarcity and global warming issues ${ }^{3}$, at least partial substitution for renewable energy is desirable (today, the main energy sources in Brazil is hydropower).

Moisture guarantees the consistency of the green pellet during the balling process and cannot be fully avoided in the processing. On the other hand, high presence in the furnace feed is one of the main bottlenecks for the drying process, where the complete release needs to take place prior to the preheating stage. In modern induration furnace operations, drying initiates up-draught (UDD), where hot air pushed upwards in temperatures around $150-200{ }^{\circ} \mathrm{C}$ through the pellet layers heating the pellets evaporates free water, which moves out from the lower layer, giving these pellets enough

*e-mail: mayconathayde@hotmail.com dry strength to resist upper layers load during the process. Nevertheless, during drying, whether the heat carrier is not hot enough (where an industrial trade-off between grate speed/ feed rate, moisture content and gas temperature is normally take in consideration), an over-wet zone may occurs at upper layers where the pellet are colder, losing its green resistance properties due moisture saturation over a certain limit $^{4}$, and become too plastic (generating clusters) and even break, due to excessive moisture (even over initial values fed to the furnace). Regarding the following zones, bed permeability will be affected thereby compromising the quality of fired pellets and performance of the operation. In addition to that, for the subsequent DDD (down-draught drying) the heat requirements to evaporate the condensed moisture increase considerably (latent heat is consumed to vaporize the condensate moisture again over the pellets) compromising energy efficiency and productivity of the furnace . $^{5}$

The downward flow has temperature limitations due to top layer pellet spalling and heat recovery restriction ${ }^{6}$. Feng et al. (2012) have gathered temperatures in the grate zone of a grate-kiln process (half of bed height of a travelling grate process), the hot draught when firstly contacts the upper layers makes a rapid pellet bed temperature rising, while the temperature in lower layers increases by no more than $10 \%$, which can be even lower if gas sensible heat is consumed to vaporize moisture at upper layers. Carvalho et al. (2017) mentioned that Pereira and Seshadri (1985) followed by several authors described single pellet drying led by three main steps: at the earlier stage, the driving force for withdrawal moisture from the surface of wet pellet is the equilibrium moisture of the hot gas. The removed moisture 
is replaced by vapor that migrates from the pellet core to the surface in a continuous process. Furthermore, evaporation from the surface reduces the moisture content throughout the system at a virtually constant volumetric rate. At an end of the constant rate period, the moisture content of the pellet surface reaches a mininum, initiate a falling in the drying rates. From this point on, the access of heat in the pellet core limits the diffusion of moisture through the pellet, thus achieving its critical moisture value.

Recently, microwave has been introduced to assist the complex heating process of several materials. Huang et al. (2012) evaluated that the method of drying iron ore with microwaves in terms of efficiency and energy is superior to conventional methods ${ }^{10}$. The major advantages of using microwaves in the industrial process are the heat transfer rate, the directional heating, the size of the equipment, the agility in switching, the absence of combustion products that contributes to the reduction of process residues and, in addition to these advantages, the equipment allows a good heating control, not requiring direct contact with the materials ${ }^{7,8}$.

According to a large microwave heating applications review by Khaled et al. (2018) ${ }^{11}$ and Haque (1999), materials behave in three ways in front of microwave radiation: they may not have any influence (transparent to the microwaves, such as silica), reflect (as with metals) or absorb these waves (water or iron-bearing materials). The same author mentioned that when such waves are absorbed, an energy transfer occurs from the microwaves to the material and as a result, the temperature increases ${ }^{18}$. The increase in temperature, or dielectric heating, is caused by the friction of the spinning dipoles or because of the migration of ionic components. By different mechanisms, iron ore and moisture are the materials that control the heating by the microwave ${ }^{12,19}$. In the case of iron ore pellets, Athayde et al. $(2018)^{13}$ explained that moisture plays an important role as an better absorber of microwave and convert the energy into heat. Despite of other carbon based materials, coal is a poor absorber. Limestone is a transparent material for microwave and finally hematite, main constituent of the pellet, have good dielectric properties.

In the present study, the application of microwave in order to support the drying process for a travelling grate furnace was studied in a pot grate. For this purpose, it was implemented a microwave generator, associating the microwave heating together with convective heating. It was assessed the benefit of over-wetting minimization at the UDD and the moisture withdrawal, pellet bed aspect was also investigated.

\section{Materials and Methods}

\subsection{Materials}

Industrial itabirite concentrate obtained from an industrial pelletizing plant located at Anchieta, Brazil was used in the laboratory pelletizing experiments. Representative samples was generated by quartering and riffling sampling methods. (ASTM E 877-03, 2003). Iron ore concentrate had a particle size of $90 \%$ passing (325\# mesh), and Blaine specific surface area was found $2030 \mathrm{~cm} 2 / \mathrm{g}$ measure according to ASTM standard (ASTM C 204-07, 2007). Additional raw material was Brazilian bentonite $(0,5 \%)$, limestone $(1,3 \%)$ and anthracite $(1 \%)$. Chemical analysis of representative pellet generated is shown in Table 1.

\subsection{Laboratory pellet-making procedure}

The green pellets were prepared according to the following balling procedure: The moist concentrate sample was weighed with defined portions of the raw material. Mixing was conducted in an Erich mixer for $80 \mathrm{~s}$. Then, the mixture was agglomerated into pellets by continuously feed into a pelletizing disc (150 cm dia.) rotating at $40 \mathrm{rpm}$ and pellet growth rate controlled by feed rate. During the mixture, the green pellet moisture was adjusted to batches of $10.3 \%$ and $10.0 \%$. Two batches of green-balls were made for each condition of final moisture, adjusted with pre-weighted moisture (Table 3).

The green pellet was sieved and classified in size range from 16.0 to $8.0 \mathrm{~mm}$ and initially separated into 4 samples of $45 \mathrm{~kg}$ for tests. The growth speed of pellets was controlled to increase the fraction between $-16+8.0 \mathrm{~mm}$. The size distribution of pellets produced is shown in Table 2 and the quality parameters of wet pellets are shown in Table 2 .

After producing green pellets and after the pot grate experiment, $100 \mathrm{~g}$ of wet pellets were randomly selected immediately. The weight of the remaining pellets was recorded and then put in a laboratory oven to dry them at $378 \mathrm{~K}$ until constant weight. A laboratory scale was used, the moisture content was calculated by wet and dry weight difference. The calculation of the percentage of humidity was performed, according to the ISO3087 standard.

Table 1. Chemical Analysis of the Pellet.

\begin{tabular}{lcccccccc}
\hline $\mathrm{Fe}(\%)$ & $\mathrm{FeO}(\%)$ & $\mathrm{SiO}_{2}(\%)$ & $\mathrm{Al}_{2} \mathrm{O}_{3}(\%)$ & $\mathrm{CaO}(\%)$ & $\mathrm{MgO}(\%)$ & $\mathrm{P}(\%)$ & $\mathrm{Mn}(\%)$ & $\mathrm{LOI}(\%)$ \\
\hline 66.95 & 0.12 & 1.96 & 0.32 & 0.65 & 0.02 & 0.046 & 0.083 & 2.65 \\
\hline
\end{tabular}

Table 2. Pellet size distribution of the pellets.

\begin{tabular}{lcccccccc}
\hline \%moisture & $\mathrm{mm}$ & +19.0 & $-19.0+16.0$ & $-16.0+12,5$ & $-12.5+9.0$ & $-9.0+8.0$ & $-8.0+6.3$ & -6.3 \\
\hline 9.98 & $\%$ & 0.00 & 4.25 & 32.55 & 58.02 & 1.89 & 1.42 & 1.89 \\
10.26 & $\%$ & 0.00 & 5.80 & 34.80 & 55.10 & 1.70 & 1.34 & 1.50 \\
\hline
\end{tabular}




\subsection{Drying experimental procedure}

The pot grate furnace has the objective of simulate conditions of an induration process. The main constituents of the furnace are: ${ }^{1}$ the combustion chamber where a burner containing LPG (liquefied petrol gas), oxygen and atmospheric air are ignited and the hot off-gases generated flows through the ${ }^{2}$ pot, where the pellets are placed during the test and fully convective heated (radiant heat from flame are retained inside of the chamber). The input energy (LPG) is a control loop with the temperature set up at the lower layer of the pot. The pot is assembled with $37 \mathrm{~cm}$ of green pellets to be burned over a $7 \mathrm{~cm}$ layer of fired pellet, placed over stainless-steel grate bars. Furthermore, the pot is located between the ${ }^{3}$ hood (connected with the combustion chamber) and the ${ }^{4}$ windbox, which conduct the gas flow (down- or upwards). For the present study, a microwave applicator was implemented at the hood (Figure 1), directing microwave generated to the pellet bed using ${ }^{5}$ waveguides made out stainless steel (non-magnetic) for safety purposed of no leakage. The ${ }^{6}$ microwave generator inserted was a microwave generator with maximum capacity of $18 \mathrm{KW}$, which operates at frequency of $915 \mathrm{MHz}$.

For this experiment the conditions for drying as well as other parameters of the experiments are given in Table 4, which were defined based on operation induration data available for industrial operations. The conditions applied in the test were: (1) Fully convective, following standard conditions and (2) mixed heating profile where the microwave was set continuously at $10 \mathrm{~kW}$ during the UDD stage.

After the test, moisture was measured at four-bed height were analyzed $(30,60,240,360 \mathrm{~mm})$. The pot grate was opened after the tests and thermal images acquired using FLIR i7 Thermal Imager.

\section{Results and Discussions}

\subsection{Pot grate temperature evaluation}

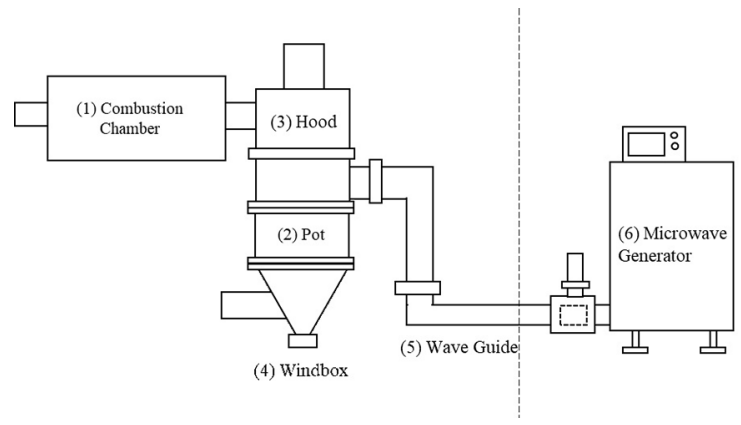

Figure 1. Scheme of pot grate adapted for microwave drying.

The constant pressure drop control-loop leads to increase of inlet air flow if the resistance through the pellet bed is lower (improving the heat transfer across the bed), in order to make the trials comparables and correlated with the industrial operation. In the fully convective mode, the pellet temperature at $60 \mathrm{~mm}$ depth from the surface does not rise to a great extent from the initial temperature in the first $200 \mathrm{~s}$, as the gas flow is colled down across the bed. Figure 2 indicate that firstly gas heat was consumed turning moisture into steam on the lower layers and secondly consumed in latent heat when moisture is re-condensate on the intermediate layer. On another hand, the microwave assisted experiment warm up pellets downwards into the pellet bed, sharply increasing the temperature of the first pellets of the upper layer showing heating rates as high as $1.5^{\circ} \mathrm{C} / \mathrm{s}$ and an average of $0.79^{\circ} \mathrm{C} / \mathrm{s}$ against only $0.14^{\circ} \mathrm{C} / \mathrm{s}$, when only convective heating is applied at the UDD. In Figure 2, it was observed a significant increase in the temperature at $60 \mathrm{~mm}$ depth, reaching the temperature of $115^{\circ} \mathrm{C}$ against $71^{\circ} \mathrm{C}$ at the end of the UDD. Afterwards, the DDD chilled the top layer, transferring the heat downwards. The pellet surface temperature above the gas dew point $\left(100-110^{\circ} \mathrm{C}\right)$ avoid the condensation of moisture.

Nevertheless, the dielectric heating is restricted to the first layers of pellets, once the wave is attenuated through the pellet bed. Saito et al. (2011) $)^{14}$ have observed low penetration depth of microwave materials with good dielectric properties

Table 3. Quality parameter of the pellet batch produced.

\begin{tabular}{lcc}
\hline Parameter & Batch 1 & Batch 2 \\
\hline Moisture (\%) & 10.26 & 9.98 \\
Wet-CS (daN/pellet) & 2.2 & 1.95 \\
Drop number (from 450mm height) & 6 & 6.5 \\
Dry-CS (@150 15 C) (daN/pellet) & 5.5 & 6 \\
\hline
\end{tabular}

Table 4. Heat pattern applied in the present study operation.

\begin{tabular}{lcccr}
\hline Zone & $\begin{array}{c}\text { Reaction Zone Length } \\
(\mathrm{m})\end{array}$ & Time (s) & Pressure Drop $(\mathrm{mmWg})$ & Temperature inlet $\left({ }^{\circ} \mathrm{C}\right)$ \\
\hline UDD & 16 & 175 & -290 & 290 \\
DDD & 31 & 340 & 250 & 280 \\
\hline
\end{tabular}


such as iron ore. Figure 3 demostrate that the lower layer closer to the hearth layer (340mm depth from surface) has no significant difference in the temperature profile between the two treatments, most likely the wave did not reach these pellets, but moisture was properly released during the UDD, which normally occurs in the region.

The mitigation of the over-wet region had an impact on the windbox temperature, based on the similar inlet temperature at the DDD zone $\left(280^{\circ} \mathrm{C}\right)$ and pressure drop in the experiment. Figure 4 indicate an improvement in the overall heat transfer rate across the pellet bed, with lower moisture at upper level it allowed increase the windbox temperature by $37^{\circ} \mathrm{C}$. A critical point at the DDD is guarantee that heat transfer gas-pellet is sufficiently low to avoid a high steam release from the pellet core and consequentely spalling, which could lead to spalling as observed by Tsukerman (2007) ${ }^{15}$. Additionally, Matos $(2007)^{16}$ presented from industrial correlation that temperature increased are responsible for $+0,01 \mathrm{MTY} /{ }^{\circ} \mathrm{C}$ in pelletizing throughput, because of the possibility to shorten the residence time of pellets inside of the furnace.

The effect of the temperature changes in the pellet bed on the moisture was measure and it is described in the following chapter.

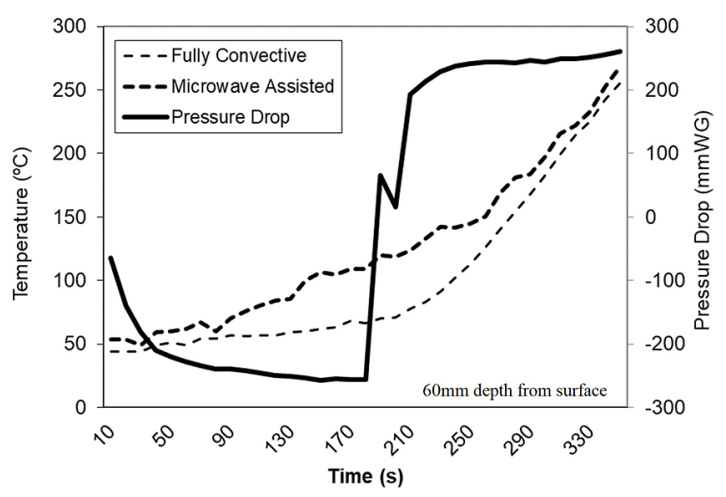

Figure 2. Temperatures profile at $60 \mathrm{~mm}$ depth from surface.

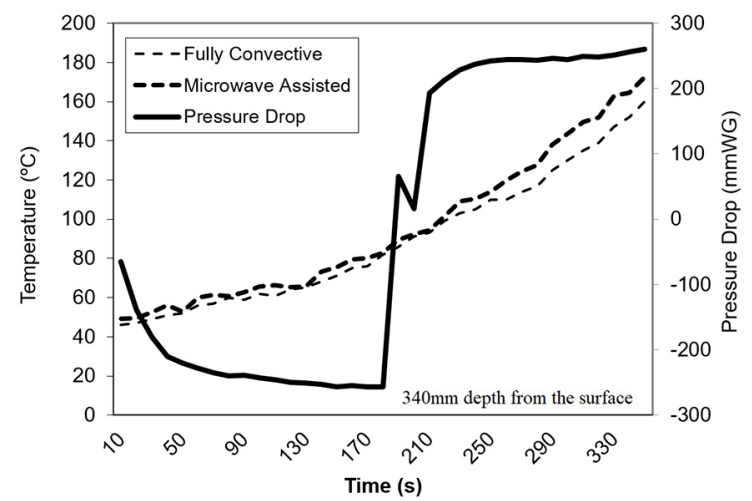

Figure 3. Temperatures profile at $340 \mathrm{~mm}$ depth from surface.

\subsection{Moisture released at pot grate experiments}

Figure 5 shows the impact of the heating distribution across the pellet bed moisture released after the experiment. The upward hot air absorbed the moisture until the saturation limit, decreasing its temperature. The moisture measured at the lowest layer, shows no difference between the heating methods (360 and $240 \mathrm{~mm}$ depth), because of the similar level of temperature achieved, as observed previously at Figure 3. On another hand, at upper layers (60 and 30 $\mathrm{mm}$ ), for the fully convective experiment, moisture presented higher than initial values $(10.2 \%$ and $10.5 \%$ above the initial $10.12 \%$ ), indicating that the air flow cooled down until the dew point, where moisture condenses over the surface of the cooler pellets, especially at $60 \mathrm{~mm}$ depth. The use of microwave at UDD had a considerable impact on those layers of pellets where moisture reduced considerably $(9.3 \%$ and $10.0 \%$ from initial $10.12 \%)$ compared with the fully convective drying, do not allow condensation. The mitigation of condensation has a direct impact on the bed permeability, as far as the physical aspect of pellets is concerned no visual cracks or deformation were observed, inferring that the drying rates were sufficient smooth for microwave power applied. According to Ljung, $(2011)^{17}$ drying is a function of an initial surface evaporation period succeeded by a period of increase in internal evaporation. Based on that, the mechanisms co-exist during a certain period of time. However, Figure 4 demonstrates that the microwave accelerates the pellet temperature towards the wet bulb temperature, making possible increase the pellet temperature sooner as the moisture content at the surface is lower.

In Figure 6, the variation of moisture in two different level of moisture has demonstrated a better efficiency with microwave assisted heating compared to the fully convective heating. The heating assisted by microwave mitigate the over-wetting of in both levels of initial moisture at the end of the UDD. However, the fully convective drying generates an over-wetting condition, which increases moisture in the upper layer by $+3.7 \%$ per $+1 \%$ of increase in bulk inicial

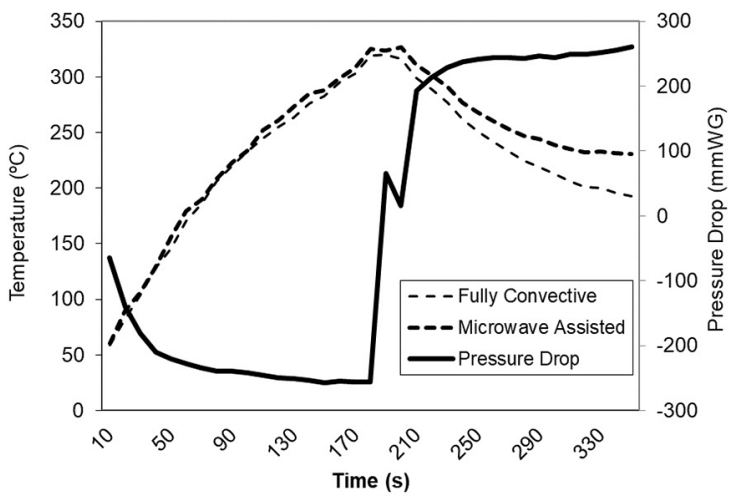

Figure 4. Windbox temperatures. 


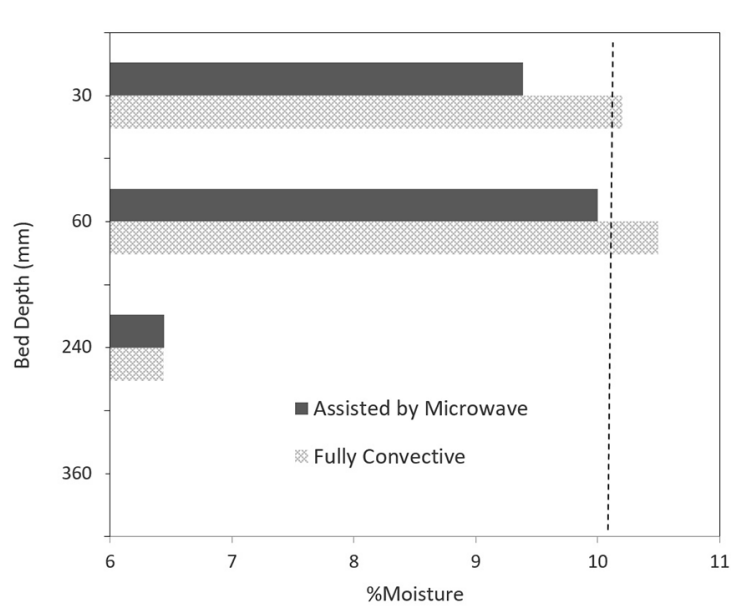

Figure 5. Effect of the Microwave on the UDD efficiency.

moisture, This behavior can be explained by Thurlby et al (1980), since, in their view, it is well established that the moisture stuck in the medium-upper layer jeopardize the pelletizing operation due the collapse of the pellets when the porous saturation is achieved ${ }^{4}$, also referred by Meyer $(1980)^{18}$ due an increase in the resistance of the air flow.

\subsection{Pellet aspect after pot grate experiments}

In Figure 7, the over-wetting zone formed can be clearly observed. Although the pot was carefully dug through the layers, some pellet cracked.

At the end of the UDD stage of each experiment, a thermal image was obtained in order to verify the heat distribution effect on the temperature of the pellet bed surface. The top layer, in Figure 8, demonstrated cross-section specific patterns for both experiments. In the microwave assisted experiment, the central part of the pot grate shows an energy concentration (Figure $8 \mathrm{~b}$ ), temperature reached $130{ }^{\circ} \mathrm{C}$ against $55^{\circ} \mathrm{C}$ in the fully convective heating (Figure $8 \mathrm{a}$ ). The reason $\mathrm{I}$ the oscillating behaviour of the microwave in multimodal ovens which generates a fairly homogeneous electromagnetic field, distributing radiations towards different directions through pot grate hood. However, this stationary waves heat more some spots of the area exposed, where the power density is considerably higher. The complex oscillating pattern of the waves could lead to thermal runaway effect ${ }^{9}$ and degradation of the pellets, which was not observed due to the moisture release at the surface. Additionally, spalling was not observed, indicating the heat rates applied were not sufficiently high despite the high temperature achieved.

\subsection{Comparison of the heating mechanisms}

The fully convective heating, in general, over-wet pellets in the intermediate and upper layers, the increase in moisture reduced the green pellet strength resulting in clusters, deformed and clogged the pellet bed voids where the gases should percolate at further downdraught steps.

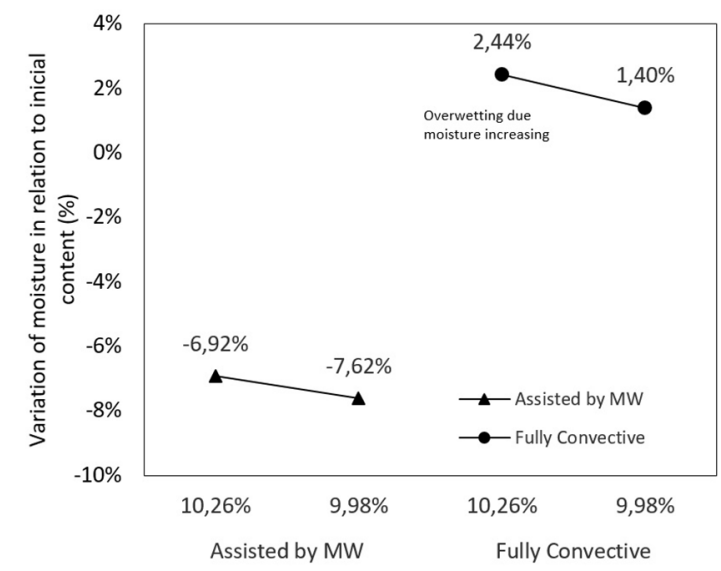

Figure 6. Effect of the total moisture content on the drying efficiency, at the top layer at the end of UDD.
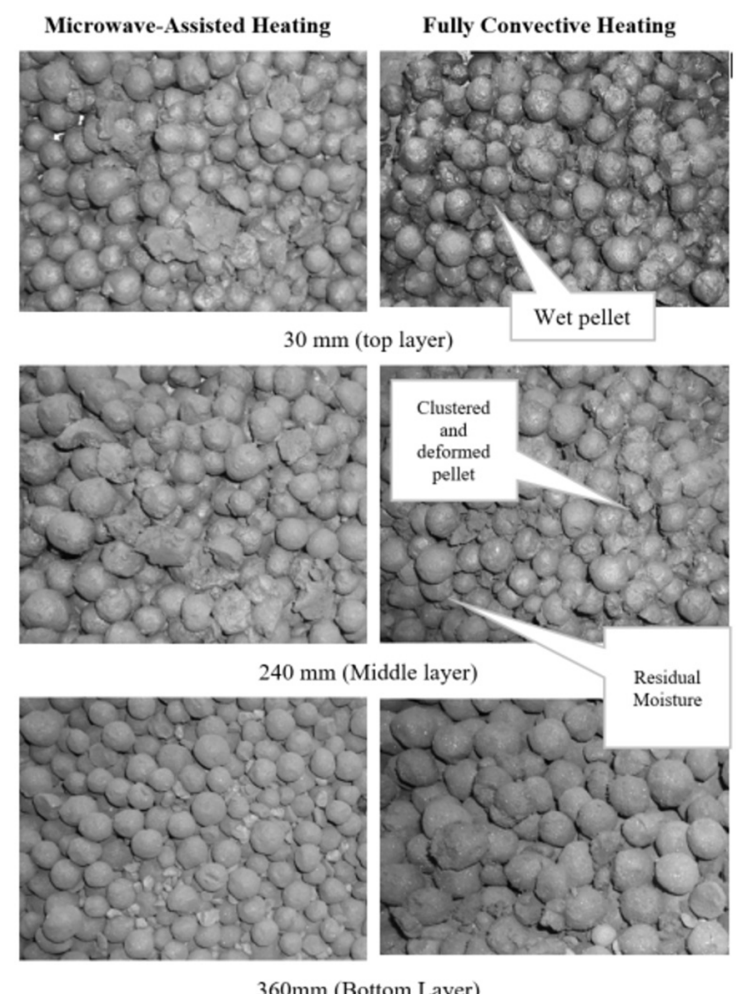

Figure 7. Visual appearance of the pellet after UDD experiment.

However, the application of microwave during the UDD stage to assisted heating minimized the clustering and deformation, in Figure 9 the mechanism is compared. The wave penetration is a function not just of wavelength, but also energy converted in heat in the first layer of the bed, which in this case is high due the high amout of moisture. Nevetheless pellets at $240 \mathrm{~mm}$ depth were almost dried (showing how deep microwave reached) whereas moist pellet (darker) at top layer is far less compared to the fully convective heating. 


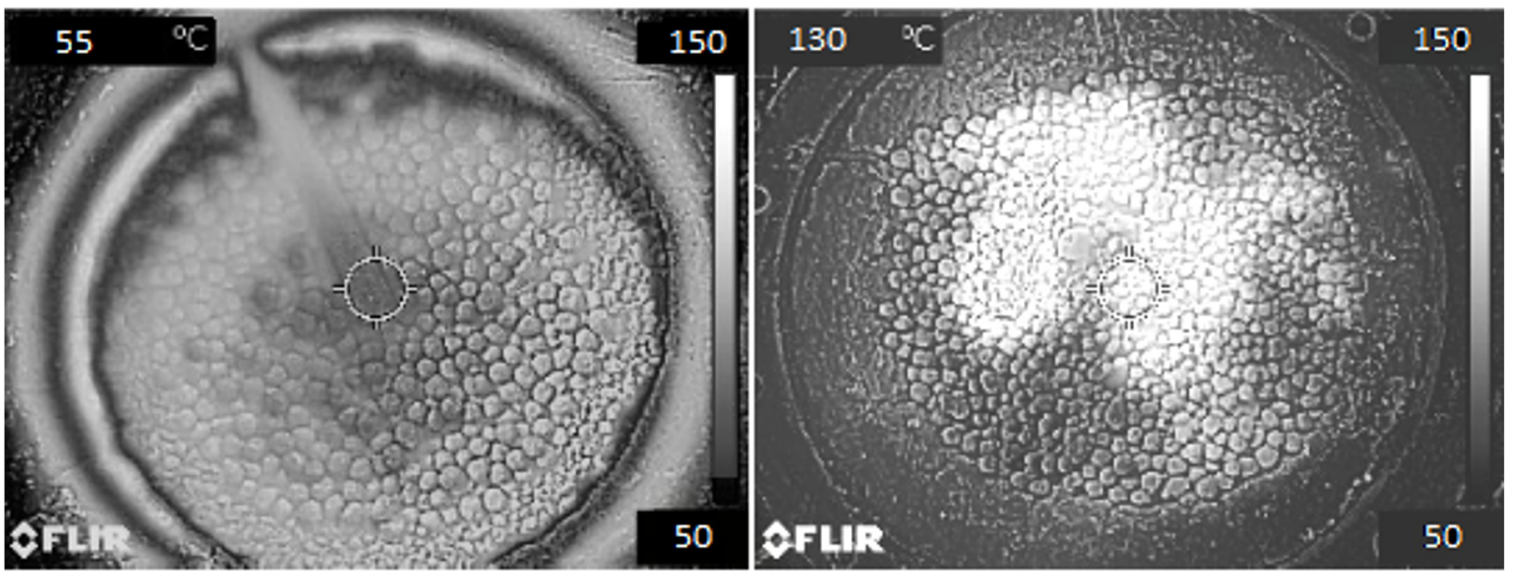

Figure 8. Heating pattern over the pan of the pot grate (a) fully conventional heating (b) assisted by Microwave.

The results represent may a significant increase in productivity of travelling grate furnaces, as DDD can operates without constraints and higher temperature. The main constraint is to eliminate water previous to the preheating zone, then maximizing the operation.

\section{Conclusion}

The present paper demonstrated through a pot grate study a breakthrough technique to improve drying efficiency through the application of microwave. The process permit:
1. Dieletric heating is much complex than fully convective heating and a new operation mode are expected due the nature of heat transfer and absorption from the different material;

2. Although high heating rates may lead to spalling of the green pellets, in the present experiments it was not observed, concluding that energy tranfer was sufficient low to release the moisture from the pellet core.

3. The heterogeneous behaviour of the application is should be improved in order to increase a energy effiency of the process. The work must continue

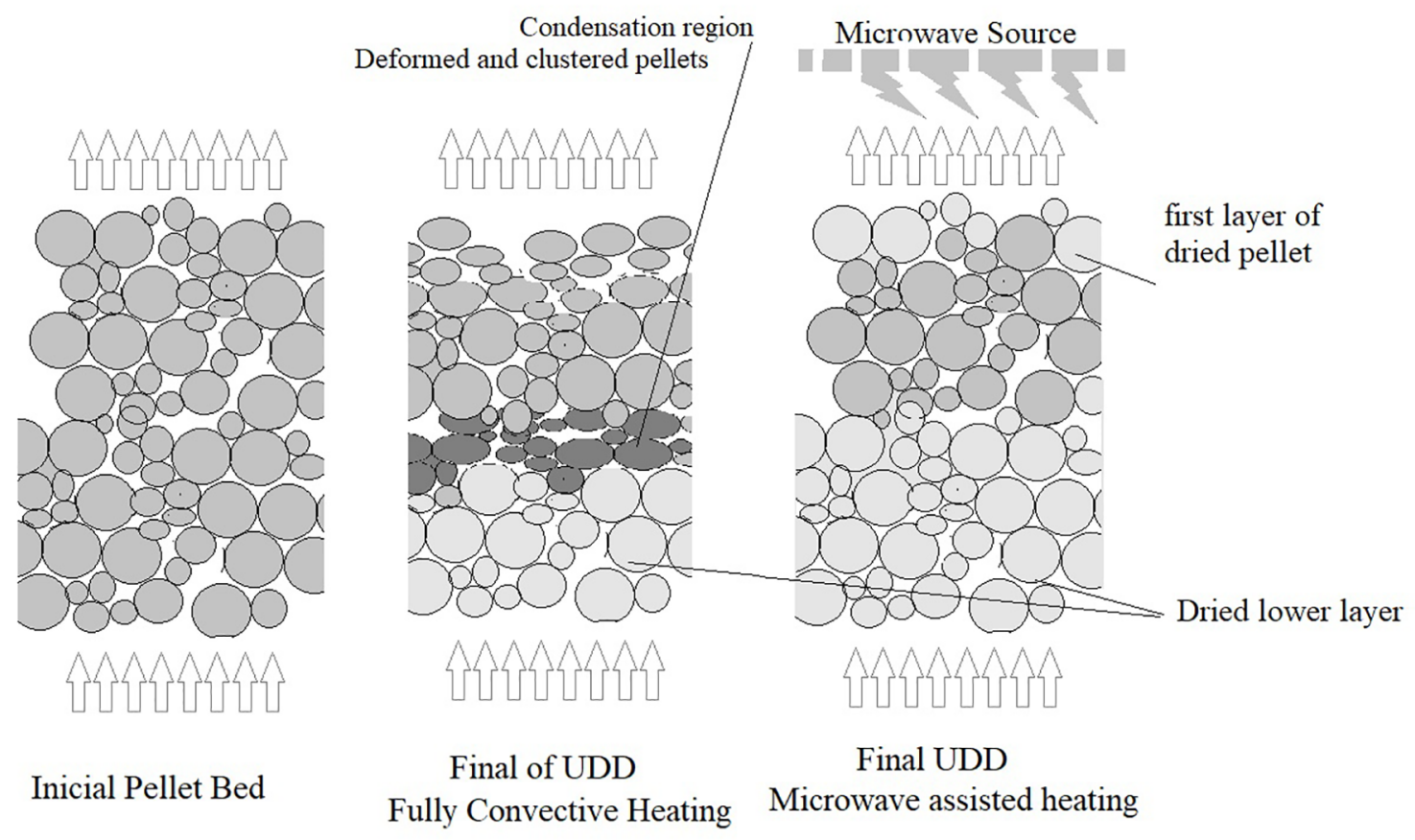

Figure 9. Mechanism of the heating and drying with fully convective and microwave assisted in the pellet bed. 
improving the applicator in order to minimize the heat distribution.

4. The microwave application minimized the dew point of the heat carrier and retention time of the green ball with excess humidity, allowing a more efficient process, for the same green pellet strength at upper layers (minimizing the influence of static load on the pellet with excess wetting).

5. The microwave assisted heating shows low influence of the initial moisture, wich impact the fully convective system leading to increase in residence time of the pellet in the furnace.

\section{Acknowledgment}

The authors would like to thank CAPES-PROEX, CNPq and FAPEMIG for stimulating and supporting research.

\section{References}

1. Forsmo SPE, Samskog PO, Björkman BMT. A study on plasticity and compression strength in wet iron ore green pellets related to real process variations in raw material fineness. Powder Technology. 2008;181(3):321-330.

2. Meyer M, Lagoeiro LE, Graça LM, Silva CJ. Phase and Microstructural Characterization of Iron Ore Pellet and their Relation with Cold Crushing Strength Test. Mineral Processing and Extractive Metallurgy Review. 2016;37(5):295-304. DOI: $10.1080 / 08827508.2016 .1200574$

3. Forsmo SPE, Apelqvist AJ, Björkman BMT, Samskog PO. Binding mechanisms in wet iron ore green pellets with a bentonite binder. Powder Technology. 2006;169(3):147-158. DOI: 10.1016/j.powtec.2006.08.008

4. Carvalho MMO, Faria DG, Pérez MG, Cardoso M, Vakkilainen EK. Review on mathematical models for travelling-grate iron oxide pellet induration furnaces. Energy Procedia. 2017;120:588595. DOI: $10.1016 /$ j.egypro.2017.07.180

5. Thurlby JA, Batterham RJ. Measurement and prediction of drying rates and spalling behaviour of hematite pellets. Transactions of the Institution of Mining and Metallurgy. Section C. 1980;89C:125-131.

6. Feng J, Xie Z, Chen Y. Temperature Distribution of Iron Ore Pellet Bed in Grate. Journal of Iron and Steel Research, International. 2012;19(2):7-11. DOI: 10.1016/s1006-706x(12)60052-1

7. Pereira ROS, Seshadri V. Secagem de pelotas de minério de ferro. Metalurgia. 1985;41(328):141-144.
8. Huang Z, Yi L, Jiang T, Zhang Y. Hot Airflow Ignition with Microwave Heating for Iron Ore Sintering. ISIJ International. 2012;52(10):1750-1756. DOI: 10.2355/ isijinternational.52.1750

9. Haque KE. Microwave energy for mineral treatment processes-a brief review. International Journal of Mineral Processing. 1999;57(1):1-24.

10. Guo S, Li W, Peng J, Niu H, Huang M, Zhang L, et al. Microwave-absorbing characteristics of mixtures of different carbonaceous reducing agents and oxidized ilmenite. International Journal of Mineral Processing. 2009;93(34):289-293. DOI: $10.1016 /$ j.minpro.2009.09.001

11. El Khaled D, Novas N, Gazquez JA, Manzano-Agugliaro F. Microwave dielectric heating: Applications on metals processing. Renewable and Sustainable Energy Reviews. 2018;82(Pt 3):2880-2892. DOI: 10.1016/j.rser.2017.10.043

12. Shaohua J, Singh P, Jinhui P, Nikoloski AN, Chao L, Shenghui $\mathrm{G}$, et al. Recent developments in the application of microwave energy in process metallurgy at KUST. Mineral Processing and Extractive Metallurgy Review. 2018;39(3):181-190. DOI: $10.1080 / 08827508.2017 .1401537$

13. Athayde M, Fonseca MC, Covcevich BM. Iron ore pellet drying assisted by microwave: A kinetic evaluation. Mineral Processing and Extractive Metallurgy Review. 2018;39(4):266275. DOI: $10.1080 / 08827508.2017 .1423295$

14. Saito Y, Kawahira K, Yoshikawa N, Todoroki H, Taniguchi S. Dehydration Behavior of Goethite Blended with Graphite by Microwave Heating. ISIJ International. 2011;51(6):878883. DOI: $10.2355 /$ isijinternational.51.878

15. Tsukerman T, Duchesne C, Hodouin D. On the drying rates of individual iron oxide pellets. International Journal of Mineral Processing. 2007;83(3-4):99-115.

16. Matos AP. Influência da temperatura, pressão, produção e granulometria no processo de secagem das pelotas cruas. [Dissertation]. Ouro Preto: Universidade Federal de Ouro Preto; 2007. 115 f.

17. Ljung AL, Lundström TS, Marjavaara BD, Tano K. Convective drying of an individual iron ore pellet - Analysis with CFD. International Journal of Heat and Mass Transfer. 2011;54(1718):3882-3890. DOI: 10.1016/j.ijheatmasstransfer.2011.04.040

18. Meyer K. Pelletizing of Iron Ores. Berlin Heidelberg: Springer-Verlag; 1980.

19. Ogunniran O, Binner ER, Sklavounos AH, Robinson JP. Enhancing evaporative mass transfer and steam stripping using microwave heating. Chemical Engineering Science. 2017;165:147-153. DOI: 10.1016/j.ces.2017.03.003 